\title{
Green synthesis of zerovalent copper nanoparticles for efficient reduction of toxic azo dyes congo red and methyl orange
}

https://doi.org/10.1515/gps-2018-0038

Received February 1, 2018; accepted April 3, 2018;

previously published online May 16, 2018

\begin{abstract}
In this study, plant-mediated copper nanoparticles (CuNPs) were synthesized. Due to its direct synthesis mechanism and eco-friendly nature, the current method accounts for the green chemistry approach using the fruit extract of Duranta erecta for the first time. The UV-visible spectrum of the CuNPs solution showed a distinct absorption peak at $588 \mathrm{~nm}$. Fourier transform infrared spectroscopy confirmed that the fruit extract is responsible for the reduction as well as the stabilization of CuNPs. X-ray diffraction patterns conform the crystalline nature of CuNPs. Energy-dispersive X-ray spectroscopy was performed for elemental analysis whereas field emission scanning electron microscopy was carried out for surface morphology. Prepared CuNPs were used for the reduction of carcinogenic azo dyes methyl orange (MO) and congo red (CR). CuNPs exhibit outstanding catalytic reduction for $\mathrm{MO}$ and $\mathrm{CR}$ in the presence of $\mathrm{NaBH}_{4}$ as reducing agents with the pseudo-first-order rate constants of $8.6 \times 10^{-3} \mathrm{~s}^{-1}$ and $5.07 \times 10^{-3} \mathrm{~s}^{-1}$ for MO and CR, respectively. Thus, natural plant materials act as cheap and environmentally friendly support for the synthesis of CuNPs and could be used for the purification of water from organic dye effluents.
\end{abstract}

Keywords: azo dye effluents; copper nanoparticles; green chemistry.

\footnotetext{
*Corresponding author: Sher Bahadar Khan, Center of Excellence for Advanced Materials Research, King Abdulaziz University, P.O. Box 80203, Jeddah 21589, Saudi Arabia; and Chemistry Department, Faculty of Science, King Abdulaziz University, P.O. Box 80203, Jeddah 21589, Saudi Arabia, e-mail: sbkhan@kau.edu.sa Muhammad Ismail, Saima Gul, M.I. Khan and Murad Ali Khan: Department of Chemistry, Kohat University of Science \& Technology, Kohat 26000, Khyber Pakhtunkhwa, Pakistan

Abdullah M. Asiri: Center of Excellence for Advanced Materials Research, King Abdulaziz University, P.O. Box 80203, Jeddah 21589, Saudi Arabia; and Chemistry Department, Faculty of Science, King Abdulaziz University, P.O. Box 80203, Jeddah 21589, Saudi Arabia
}

\section{Introduction}

Green chemistry is generally the use of methods and techniques to eliminate or reduce the generation or use of feedstock, by-products, products, reagents, and solvents that are very harmful to human beings or to the environment. Thus, the objective of green chemistry is to eliminate hazards related to the methodology and products that are important for the economy of the world and to maintain the good quality of living that we enjoy through chemistry [1]. Due to the rapid development of nanomaterials, it has seen application in different fields such as antibacterial activities, catalysis, photographic material, sensors, and materials like semiconductors [2-4]. Currently, a large number of nanoparticles of metal sulfides, metal oxides, metal chlorides, and pure metal have been effectively synthesized using different methods [5]. Different physical, chemical, and biological synthesis methods have been established for the nanoparticles. To avoid the utilization of hazardous chemicals and to increase the awareness of green chemistry, an increase in the development of nontoxic, clean, easy, and environmentally friendly methods for nanoparticle synthesis is required. The biological synthesis of metal nanoparticles tender various advantages over chemical and physical methods as these methods can be carried out more easily than conventional methods [6].

Among the different metal nanoparticles, copper nanoparticles (CuNPs) have attracted significant attention due to their strong optical, catalytic, electrical, mechanical, antifungal, and antibacterial properties [7, 8]. CuNPs have advantages over other metal nanoparticles as they are cheap and, in moderate reaction conditions, provide better yields and have short reaction times in contrast with conventional catalysts [9]; thus, this is the basic stimulus for the synthesis of CuNPs.

Different synthesis methods are carried out for CuNPs such as a reduction by chemical, electrochemical, thermal decomposition, and irradiation methods as well as photochemical, vacuum vapor deposition, and sol-gel methods. To avoid oxidation, the aforementioned methods were 
generally carried out in nonaqueous solvents, at low starting concentration, mostly using an inert atmosphere $[10,11]$. Mostly, the use of soluble surfactants or polymers as a capping agent in the preparation of CuNPs in aqueous solution is attractive because it avoids the use of organic solvents and the absence of subsequent pollutants. A very limited amount of literature is available up till now because copper oxidizes very easily [12]. In fact, large numbers of plants, fungi, and bacteria have been used for the green synthesis of CuNPs [13].

Dyes are recalcitrant and colored molecules, which are not so easy to degrade biologically and are resistant to degradation due to their synthetic origin and complex chemical structure $[14,15]$. Because synthetic azo dyes are extensively used in various fields of science and technology, dye contamination is becoming a major cause of environmental pollution nowadays. All over the world, different industries release approximately 150 tons of dyes each day into aquatic environments $[16,17]$. The color of these dyes is highly visible in aquatic environments and affects water transparency, aesthetics, and also the solubility of gas in water bodies. A large number of dyes are carcinogenic in nature and are made up from known aromatic compounds such as benzidine and others. Therefore, color removal has become of major scientific interest $[18,19]$. The removal of dye effluents has received increasing awareness, and thus different biological, physical, and chemical treatment methods have been used for dye elimination from aqueous environments, such as filtration, reverse osmosis, coagulationflocculation, precipitation, ion-exchange adsorption, chlorine or hydrogen peroxide, membrane systems, and bacterial cells [20]. The aforementioned conventional methods available for wastewater treatment are slow and nondestructive. Therefore, an efficient catalyst is needed for the removal of these highly carcinogenic substances. Copper nanoparticles should be used as effective catalysts due to their different electronic properties and large surface-to-volume ratio. Catalytic degradation using zerovalent CuNPs is an important way of eliminating dye pollutants without the production of secondary toxic substances [2, 8].

In this article, we are presenting a novel green method, i.e. aqueous phase synthesis of CuNPs, using natural products such as plant extracts as capping as well as reducing agents. The main objective of the current study was to perform a catalytic efficiency of green synthesized CuNPs as a catalyst in the degradation of commercially available carcinogenic azo dyes congo red (CR) and methyl orange (MO) from the aqueous solution.

\section{Materials and methods}

\subsection{Materials}

All the chemicals and solvents used were of analytical grade. Sodium borohydride $\left(\mathrm{NaBH}_{4}\right)$ and copper sulfate pentahydrate $\left(\mathrm{CuSO}_{4} \cdot 5 \mathrm{H}_{2} \mathrm{O}\right)$ were purchased from BDH Chemicals England. MO and CR dyes were purchased from Merck (Germany). In the synthesis of $\mathrm{Cu}$ nanoparticles, deionized (DI) water was used.

\subsection{Preparation of aqueous fruit extract}

Ripened Duranta erecta fruits were used for the preparation of aqueous extract. $D$. erecta fruits weighing $30 \mathrm{~g}$ were carefully washed with double-distilled water, dried, and then crushed into $100 \mathrm{ml}$ DI water using an electric blender for extract preparation. Then, it was filtered through Whatman No. 42 filter paper (pore size $90 \mu \mathrm{m}$ ) followed by filtration through $25 \mu \mathrm{m}$ size filter paper. The filtrate was stored in a refrigerator $\left(-4^{\circ} \mathrm{C}\right)$.

\subsection{Synthesis of CuNPs}

For aqueous phase synthesis of CuNPs, $D$. erecta fruit extract was used as capping as well as reducing agents. An approximately $5 \mathrm{~mm}$ solution of $\mathrm{CuSO}_{4} \cdot 5 \mathrm{H}_{2} \mathrm{O}$ was prepared in DI water and used for the synthesis of CuNPs. For the preparation of CuNPs, $85 \mathrm{ml}$ of $\mathrm{CuSO}_{4} \cdot 5 \mathrm{H}_{2} \mathrm{O}$ solution was taken in $200 \mathrm{ml}$ Erlenmeyer flasks to which $15 \mathrm{ml}$ of aqueous fruit extract was then added. The reaction mixture was allowed to stand with constant stirring at $80^{\circ} \mathrm{C}$. The color of the solution changed from light yellow to dark brown after $1 \mathrm{~h}$, indicating the formation of monodispersed CuNPs. The reaction mixture of green synthesized CuNPs was then subjected to centrifugation at $6000 \mathrm{rpm}$ for $10 \mathrm{~min}$. The resulting pellet was washed with ethanol followed by DI water, and then dried at room temperature.

\subsection{Catalytic reduction study of dyes}

For the catalytic reduction study, a quartz cuvette was used as a reaction vessel. For the reaction, approximately $3 \mathrm{ml}$ of dye solution $(0.03 \mathrm{~mm})$ was taken in a cuvette in which $0.5 \mathrm{ml}$ of freshly prepared $\mathrm{NaBH}_{4}(0.2 \mathrm{M})$ was then added and its UV-visible spectra was recorded. For the reduction of dyes, $5.0 \mathrm{mg}$ of dried CuNPs was introduced into the reaction mixture. The variation in the absorption intensity was monitored continuously after each minute using a UV-visible spectrophotometer. Upon completion of the reduction, the nanoparticles were recovered from the reaction by centrifugation and washed with freshly prepared DI water and dried for the next use.

\subsection{Instruments}

2.5.1 UV-visible analysis: The formation of green synthesized CuNPs was confirmed using a UV-visible spectrophotometer 
(Shimadzu 1800). Catalytic reduction spectra of dyes were recorded at a range of 200 to $800 \mathrm{~nm}$.

2.5.2 Fourier transform infrared analysis: For the confirmation of stabilizing agents, a Fourier transform infrared (FT-IR) analysis of the prepared CuNPs was performed. FT-IR spectral measurements were carried out on a spectrum-100 FT-IR spectrophotometer purchased from Bruker (Alpha, USA) using a $\mathrm{KBr}$ pellet method for nanoparticles within a fixed spectral range, i.e. $4000-400 \mathrm{~cm}^{-1}$.

2.5.3 Field emission scanning electron microscopy and energydispersive X-ray analyses: A JEOL (JSM-7600F, Japan) field emission scanning electron microscopy (FE-SEM) instrument was used for determination of the morphology and mean diameter of the prepared CuNPs. JEOL (JSM-7600F, Japan) system was used for confirmation of elemental analysis.

2.5.4 Thermogravimetric analysis (TGA): TGA of prepared CuNPs was carried out to study the amount of stabilizing agents and thermal behavior of CuNPs under high temperature. TGA SII Exstar 6000, thermogravimetric/differential thermal analysis (TG/DTA) 6300 thermal analyzer (Perkin Elmer Life and Analytical Sciences, USA) instrument was used at a heating rate of $10^{\circ} \mathrm{C} / \mathrm{min}$ from $27^{\circ} \mathrm{C}$ to $800^{\circ} \mathrm{C}$ under nitrogen atmosphere.

2.5.5 X-ray diffraction analysis: To study the crystal structure and average crystallite size of synthesized CuNPs, X-ray diffraction (XRD) analysis was carried out. XRD machine PAN JDX-3532 JEOL Japan analytical diffractometer having $2 \theta$ range $20^{\circ}$ to $70^{\circ}, \mathrm{K} \alpha=1.5$, at room temperature. The Scherrer equation was used to calculate the average crystallite size of the catalysts.

$$
L=k \lambda / \beta_{1 / 2} \cos \theta
$$

\section{Results and discussion}

\subsection{Synthesis of CuNPs and UV-visible analysis}

In the current work, $D$. erecta fruit extract was used for the synthesis of stable $\mathrm{Cu}$ nanoparticles in aqueous phase. The formations of CuNPs were confirmed using UV-visible spectra due to surface plasmon resonance. The UV-visible absorption spectra of synthesized CuNPs were recorded at fixed wavelengths from 200 to $800 \mathrm{~nm}$. The UV spectrum of $D$. erecta fruit extract shows absorption bands at 338 and $226 \mathrm{~nm}$, which is characterized due to the absorbance of benzoyl-related systems of the biomolecules [21-23]. The characteristic absorption peak of $\mathrm{Cu}$ colloids was observed at $588 \mathrm{~nm}$, as shown in Figure 1. Surface plasmon is the electron excitation in the conduction band of the nanoparticles surface. The metal nanoparticles providing the characteristic absorption spectra in the UVvisible region are called surface plasmon resonance of nanoparticles. It has been reported in the literature that

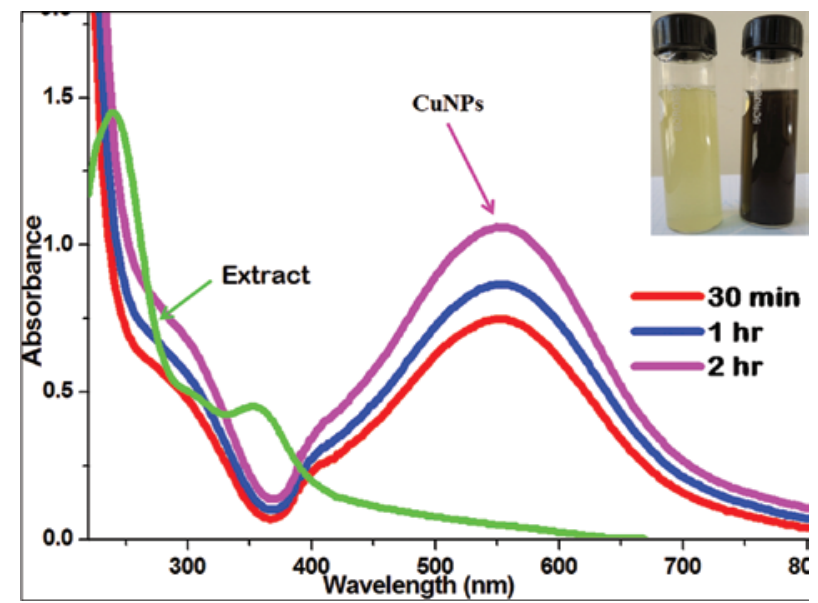

Figure 1: UV-visible spectra of $D$. erecta fruit extract and synthesized CuNPs (inset shows the change in color after the formation of CuNPs).

the surface plasmon resonance band of $\mathrm{Cu}$ nanoparticles provides absorption from 570 to $600 \mathrm{~nm}$ [24, 25]. The CuNPs surface plasmon band stability at $588 \mathrm{~nm}$ confirms the formation of $\mathrm{Cu}$ nanoparticles and also shows that particles in the solution are monodispersed with no sign of agglomeration.

\subsection{FT-IR discussion of CuNPs}

FT-IR spectroscopy is an important tool for the detection of functional groups of biomasses, which are responsible for capping and stabilizing agents of the prepared CuNPs. The FT-IR spectrum of $D$. erecta fruit extract show absorption bands at 3373, 2936, 1617, 1493, 1269, 1149, and $815 \mathrm{~cm}^{-1}$ (Figure 2). The broad band at $3373 \mathrm{~cm}^{-1}$ may be attributed to

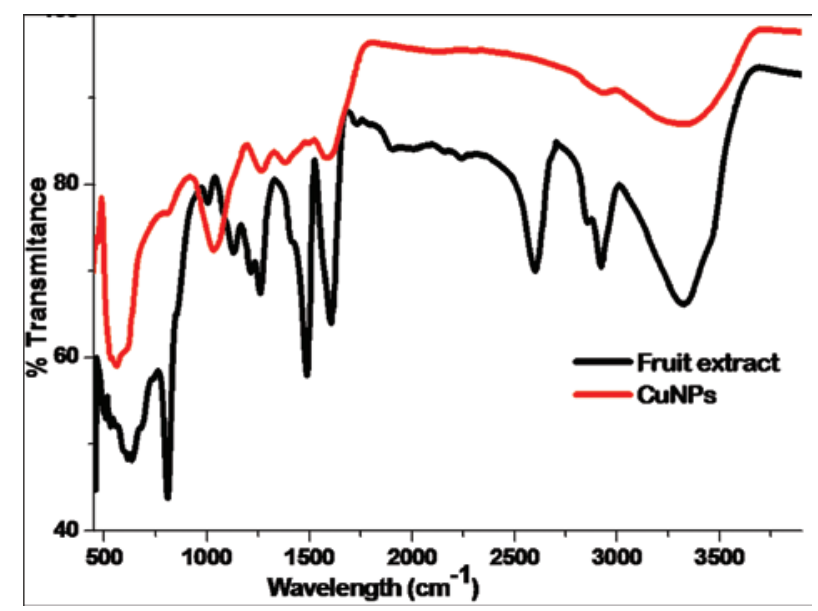

Figure 2: FT-IR of $D$. erecta extracts and synthesized CuNPs. 
the stretching vibration of primary and secondary amine and amide linage of proteins [26]. The band at 2936 may be assigned to the $\mathrm{C}-\mathrm{H}$ of methylene [27]. The intense peak at 1617 and $1493 \mathrm{~cm}^{-1}$ could be assigned to the carbonyl $(\mathrm{C}=0)$ stretching vibration of the amide linkage and stretching vibration of C-N of aromatic amine, respectively [28, 29]. The band at $1269 \mathrm{~cm}^{-1}$ may be assigned to C-O stretching $[30,31]$. The intense absorption band at $1052 \mathrm{~cm}^{-1}$ could be assigned to $\mathrm{C}-\mathrm{O}-\mathrm{C}$ stretching vibration [32], whereas the band at $815 \mathrm{~cm}^{-1}$ is assigned to $p$-disubstituted benzene $[26,27]$.

The bands observed in the FT-IR spectrum of CuNPs were at $3360,1620,1415,1288,1052$, and $528 \mathrm{~cm}^{-1}$, as shown in Figure 2. The spectrum of CuNPs show all the characteristic peaks of $D$. erecta extract along with a new peak at $528 \mathrm{~cm}^{-1}$, which corresponds to the $\mathrm{Cu}-\mathrm{O}$ bond [33]. The slight shift in the FT-IR bands of CuNPs from that of $D$. erecta extract along with the new peak at $528 \mathrm{~cm}^{-1}$ confirmed the formation of CuNPs. The results obtained from the FT-IR spectra confirmed that nanoparticles are coated with biomolecules, especially with the amino acid residues of the proteins. The amino acid residues of proteins have a strong ability to bind with metal by coating their surface and preventing them from aggregation and are responsible for stabilizing. Thus, from the above discussion, it can be concluded that biomass (protein, phenolic, and alcoholic compounds) perform the function of stabilizing agents for CuNPs.

\subsection{FE-SEM analysis of CuNPs}

For identification of size and surface morphology, FE-SEM was used. FE-SEM images of the green synthesized CuNPs were found to be spherical in shape without aggregation (Figure 3). From the images, it has been confirmed that the synthesized CuNPs are stabilized by biomolecules present in $D$. erecta fruit extract. It has been reported in the literature that the optical and electronic properties of metal nanoparticles are shape dependant [34]. For size and surface morphology determination, FE-SEM has previously been used by several investigators for the characterization of metal nanoparticles. The average size of the synthesized CuNPs was found to be $70 \mathrm{~nm}$ having monodispersity (Figures 3B and 4A). Higher magnification FE-SEM images show the well-defined surface modification and coating of biomolecules, which stabilize the fine surface of CuNPs.

\subsection{EDX investigation of CuNPs}

The energy-dispersive X-ray (EDX) profile of the prepared nanoparticles shows strong elemental signals of copper and confirms the presence of copper in nano form, as shown in Figure 4B. This shows that prepared CuNPs contain only metallic copper lacking any other impurities. The EDX pattern clearly shows that the CuNPs are

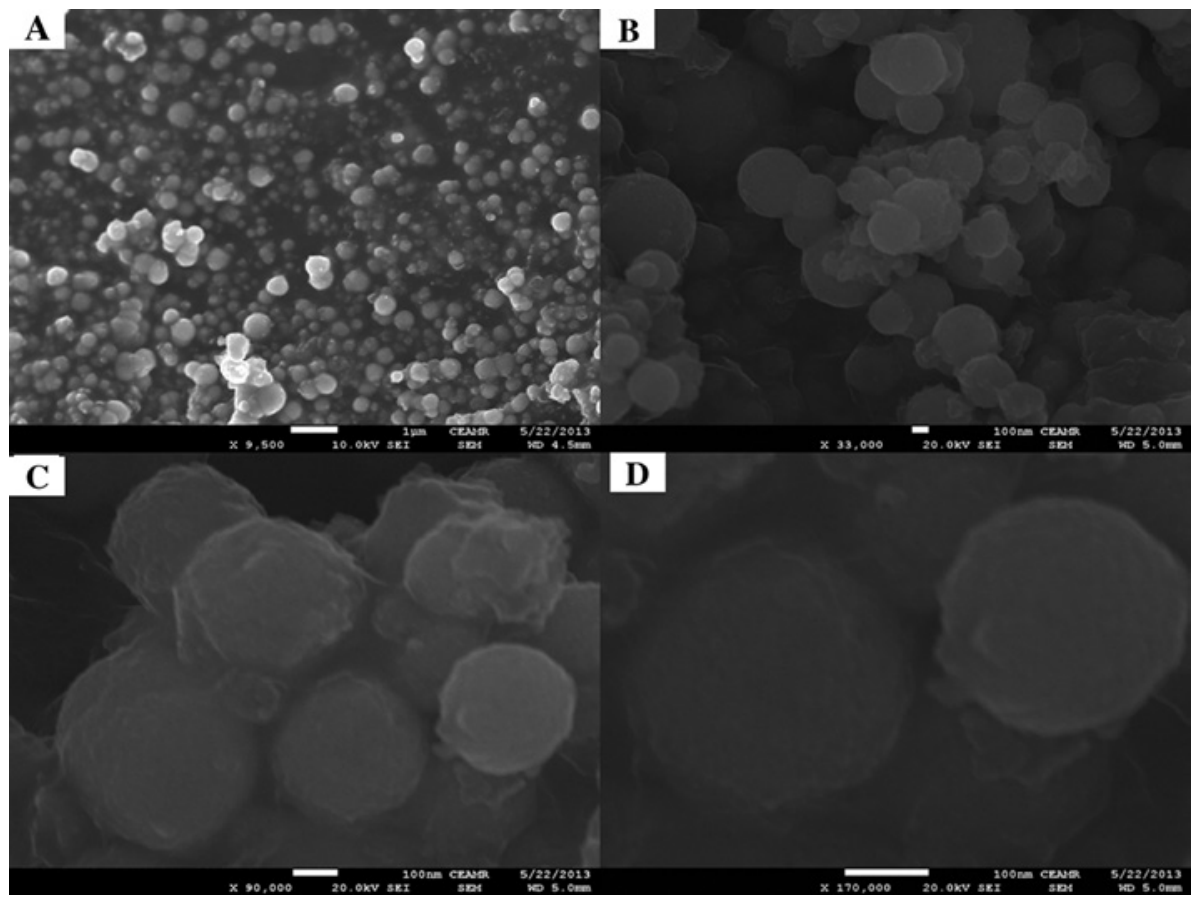

Figure 3: Low to high magnification FE-SEM images of prepared CuNPs. 


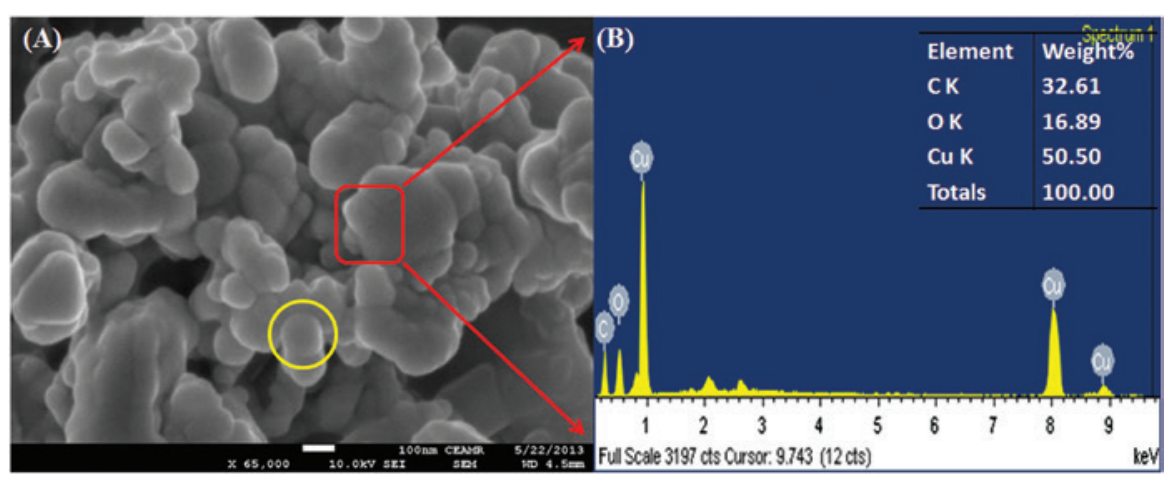

Figure 4: (A) High-resolution FE-SEM image and (B) EDX investigation of prepared CuNPs.

crystalline in nature. The EDX profile obtained from $D$. erecta extract capped CuNPs confirmed the presence of CuNPs mostly showed strong signal energy peaks for the copper atoms at 1.0 and $8.0 \mathrm{keV}$. The previous studies carried out for individual spherical-shaped CuNPs also show strong signal peaks at 1.0 and $8.0 \mathrm{keV}$ [35-37]. Approximately $50.5 \%$ weight of copper was present in the prepared nanoparticles whereas the remaining $49.5 \%$ were carbon and oxygen present in organic molecules, which act as capping molecules surrounding the nanoparticles. The excess carbon is due to the coating that was used in the analysis. These values show agreement with the TG analysis of the prepared CuNPs, which also show a $49.2 \%$ weight loss of the capping agents. Because the nanoparticles are spherical, isolated, and monodispersed without impurities, monodispersities of CuNPs are very useful features for material scientists to improve various applications related to CuNPs. The weight percentages of different elements in the CuNPs were $32.61 \%$ C, $16.89 \%$ O, and $50.50 \% \mathrm{Cu}$, as shown in Figure 4B.

\subsection{TG analysis of CuNPs}

The presence of biomolecules, which act as capping as well as reducing agents present on the surface of CuNPs, was further confirmed by TGA, as shown in Figure 5. Three distinct exothermic peaks were observed in the DTA thermogram recorded in the temperature range of $27^{\circ} \mathrm{C}$ to $800^{\circ} \mathrm{C}$. The three different weight losses observed were at $39^{\circ} \mathrm{C}$ to $115^{\circ} \mathrm{C}, 162^{\circ} \mathrm{C}$ to $192^{\circ} \mathrm{C}$, and $220^{\circ} \mathrm{C}$ to $400^{\circ} \mathrm{C}$. The first $13 \%$ weight loss observed from $39^{\circ} \mathrm{C}$ to $115^{\circ} \mathrm{C}$ is attributed to the physically adsorbed water molecules on the surface of CuNPs. Afterward, there was continuing weight loss occurring until $400^{\circ} \mathrm{C}$. The second and third weight losses that appeared in the thermogram were found to be at approximately $36.25 \%$. It is believed that the total

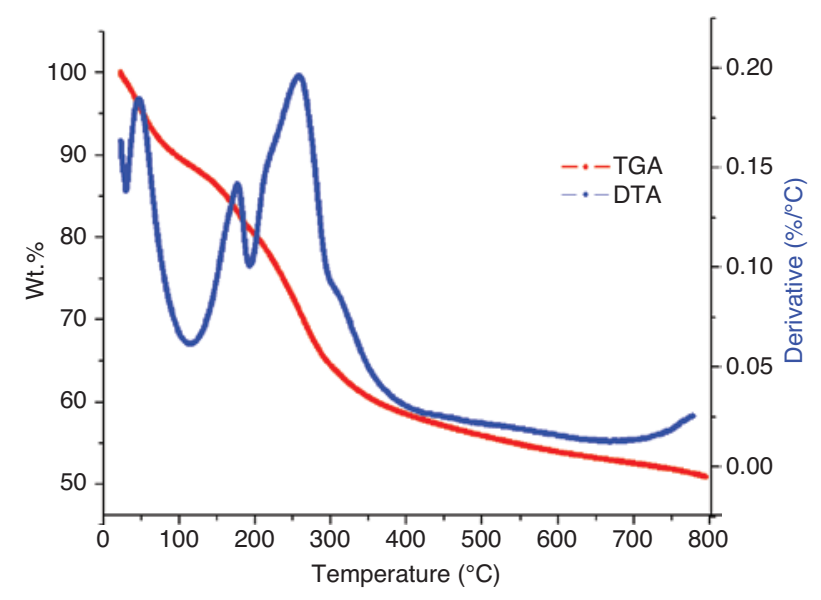

Figure 5: TGA/DTA thermogram of $D$. erecta synthesized CuNPs.

weight loss amounting to $49.25 \%$ of the sample weight is due to physically adsorbed water molecules and desorption of biomolecules that are responsible for stabilization as well as also for reduction of CuNPs. Thus, the D. erecta fruit extract are likely to be made up of biomolecules such as proteins, enzymes, and polyphenoles that are responsible for the stabilizing of CuNPs, as reported previously in the literature $[38,39]$. The total weight loss observed in the thermogram was $49.25 \%$, which shows that $50.75 \%$ of the metallic copper is present in the prepared CuNPs. This evidence also supports the EDX analysis of prepared CuNPs.

\subsection{XRD analysis of CuNPs}

The XRD patterns of $D$. erecta synthesized CuNPs is shown in Figure 6. The XRD pattern of the synthesized CuNPs is similar to previous reports [40]. All the possible peaks observed indicate metallic copper, which also show the polycrystalline nature of CuNPs. In the XRD pattern, two distinct diffraction peaks for CuNPs are observed with a 


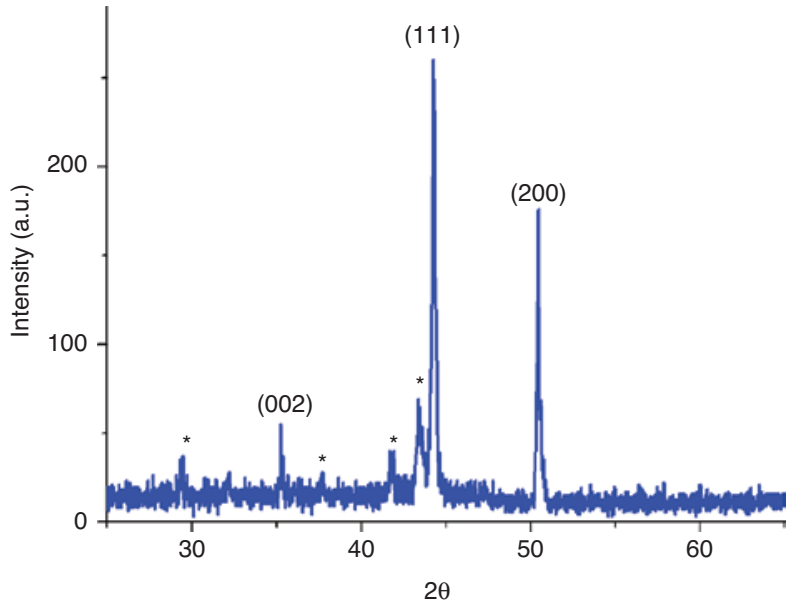

Figure 6: XRD pattern of $D$. erecta synthesized CuNPs.

$2 \theta$ value of $43.74^{\circ}$ and $50.78^{\circ}$ representing Bragg's reflections of [111] and [200] planes of fcc crystal structures of CuNPs [40, 41]. The average crystallites size of copper was calculated from the Scherrer equation. The average crystallite size of the CuNPs was $76 \mathrm{~nm}$, which is ably supported by high-resolution FE-SEM images as well. The small diffraction peak at $35.5^{\circ}$, which corresponds to the Bragg's reflections of [002] may be due to the formation of copper oxide [42]. Here, the formation of copper oxide in small quantities cannot be ignored. Some unidentified peaks at $29.05^{\circ}, 38.2^{\circ}, 41.53^{\circ}$, and $42.53^{\circ}$ were assigned $\left({ }^{\star}\right)$. These unassigned peaks might be due to the crystallization of biomolecules.

\subsection{Catalytic reduction of dyes}

\subsubsection{Catalytic reduction of MO}

With the development of industries, human beings face serious environmental disputes due to the release of a large number of pollutants, especially dyes and other organic molecules, in the aqueous environment. The release of polluted water into the ecosystem is a major threat to aquatic life as well as human health. The intense dark color of azo dyes is due to the presence of azo $(-\mathrm{N}=\mathrm{N}-)$ groups in their chemical structure $[43,44]$. Among the dyes, the azo group constitutes the largest group of organic synthetic dyes and is widely used by the cosmetic, food, paper and pulp, and textile industries. An anionic azo dye MO has been used frequently as an indicator in laboratories as well as in the plastics, cosmetics, paper, textile, pharmaceutical, rubber, and printing industries $[45,46]$. Due to the lower biodegradability of
MO, the presence of the azo group makes it hazardous for the environment. MO leads to several health risks such as vomiting, diarrhea, breathing, and nausea [47]. Therefore, the elimination and degradation of MO dye from aqueous environments are important. In the past decades, there has been growing interest in catalytic hydrogenation by heterogeneous catalyst [48-50].

The discharge of azo dye waste effluents from various industries, especially the textile industries, into the aqueous environment is a serious threat. Thus, the development of new methodologies for the degradation/ removal of azo dyes is of great interest. The aqueous MO solution gives a strong peak at $468 \mathrm{~nm}$ and a small absorption peak at $278 \mathrm{~nm}$. It has been reported in the literature that the reduction of $\mathrm{MO}$ dye alone by $\mathrm{NaBH}_{4}$ is favorable thermodynamically but, kinetically, this reaction is extremely slow [51]. In the absence of a suitable catalyst, the peak intensity at $468 \mathrm{~nm}$ remains constant for MO even for several hours $[8,52]$.

For catalytic reduction of MO, firstly, $3 \mathrm{ml}$ of $0.03 \mathrm{~mm}$ solution was taken in a quartz cuvette and then $0.5 \mathrm{ml}$ of aqueous $\mathrm{NaBH}_{4}$ solution was added. UV-visible spectra of MO gives a strong peak at $468 \mathrm{~nm}$ and a weak peak at $278 \mathrm{~nm}$. In the absence of a catalyst, the intensity of the peak remains constant at $467 \mathrm{~nm}$. However, the decrease in peak intensity at both 278 and $468 \mathrm{~nm}$ starts after the introduction of $5 \mathrm{mg}$ of CuNPs. The catalytic activity of CuNPs was recorded by measuring their UV-visible spectra with a time interval of $30 \mathrm{~s}$ between measurements, as shown in Figure 7A. With the addition of CuNPs, the intensity of both peaks at 278 and $468 \mathrm{~nm}$ decreases. However, the peak maxima at $278 \mathrm{~nm}$ slightly shifted toward the lower wavelength with an increase in intensity and finally reached $250 \mathrm{~nm}$, as shown in Figure 7A. Thus, the gradual disappearance of the peak at $468 \mathrm{~nm}$ was due to the degradation of MO. Generally, $\mathrm{NaBH}_{4}$ in the presence of active catalyst reduced $\mathrm{MO}$ molecule at the azo site by generating low molecular free amino group compounds. Thus, the formation of a new peak at $250 \mathrm{~nm}$ was from the generation of free amino groups (hydrazine derivative) compounds during the MO reduction [15].

Percent reduction of the MO was calculated from the plot of UV-visible spectra by using equation (2)

$$
\text { Percent reduction }=100-\left(A_{t} \times 100 / A_{0}\right)
$$

where $A_{0}$ is the initial absorbance at $\lambda_{\text {max }} 467 \mathrm{~nm}$ and $A_{t}$ is the absorbance at time $t$. Here, a $96 \%$ reduction of MO in the presence of $\mathrm{NaBH}_{4}$ and CuNPs takes place in $4 \mathrm{~min}$, as shown in Figure 7C. The reduction of MO follows the pseudo-first-order reaction as reported in the literature. 

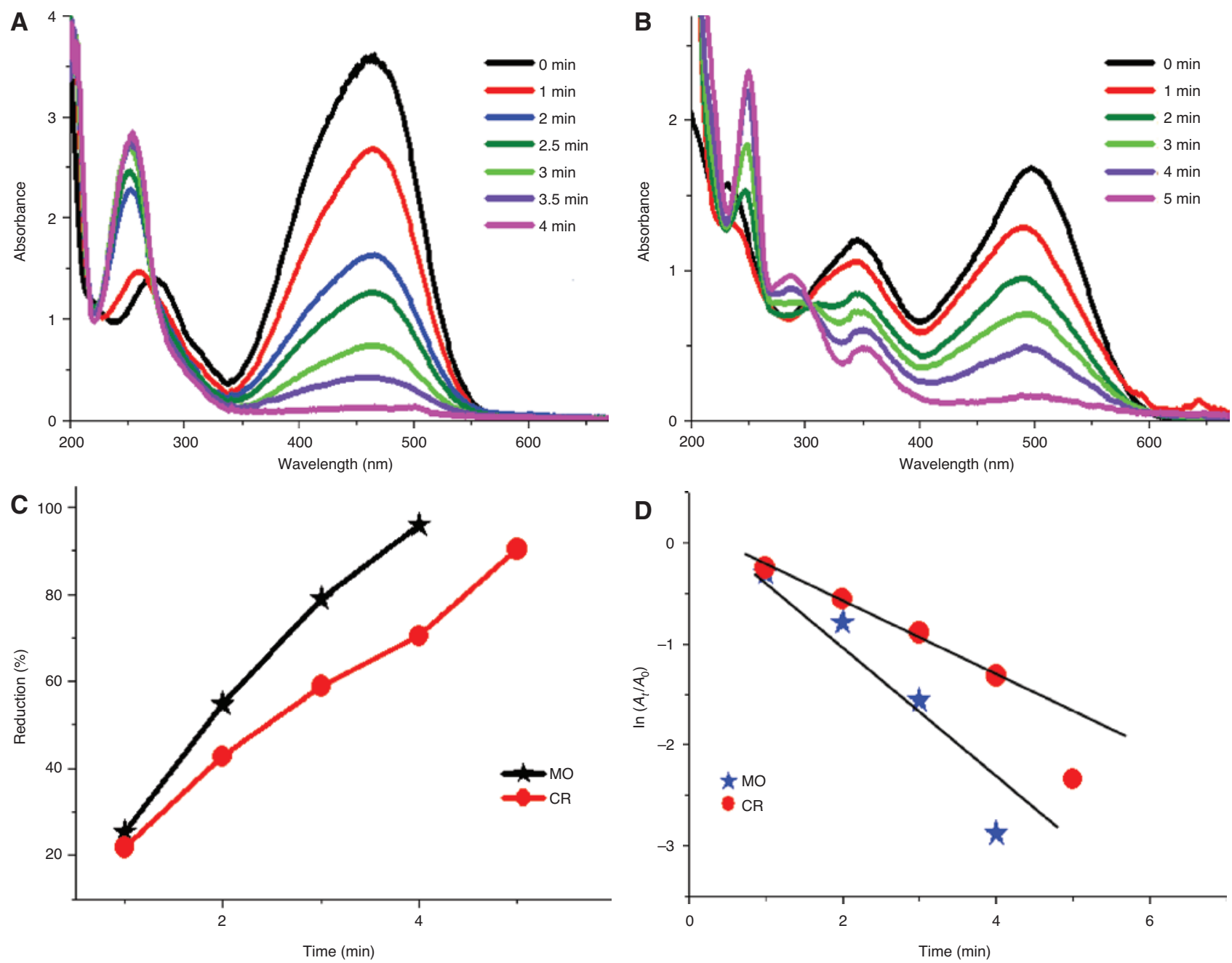

Figure 7: UV-visible spectra of (A) MO reduction by $\mathrm{NaBH}_{4}$ and CuNPs, (B) $\mathrm{CR}$ reduction by $\mathrm{NaBH}_{4}$ and CuNPs, (C) comparative percent reduction of $M O$ and $C R$, and (D) plot of $\ln \left(A_{t} / A_{0}\right)$ versus time for $M O$ and CR. Experimental conditions ( $3 \mathrm{ml}$ of aqueous dye solution $+0.5 \mathrm{ml}$ of $0.2 \mathrm{M}$ aqueous $\mathrm{NaBH}_{4}$ solution $+5 \mathrm{mg}$ of CuNPs).

The apparent rate constant $\left(k_{\text {app }}\right)$ of the pseudo-firstorder kinetic was calculated from the plot of $\ln \left(A_{t} / A_{0}\right)$ versus time of reduction (as given in Figure $7 \mathrm{D}$ ) using equation (3)

$$
\ln A_{t} / A_{0}=-k K t=-k_{\text {app }}
$$

Thus, the $k_{\text {app }}$ calculated from the slope was $8.6 \times 10^{-3} \mathrm{~s}^{-1}$.

\subsubsection{Catalytic reduction of CR}

Congo red, an anionic di-azo dye, is also commonly used in different industries. CR is very important among the various azo dyes due to its use in food, textile, paper and pulp, cotton, silk, and wool industries. It is used as a biological stain in medicine for the diagnosis of amyloidosis and is also used as an indicator in acidic medium $[53,54]$. Beside the wide variety of applications of $\mathrm{CR}$, it produces harmful effects on animals. CR causes skin and eye irritation, vomiting, diarrhea, gastrointestinal irritation, and others. Long-term exposure to CR can cause liver tumors in women [55]. It has been reported that $\mathrm{CR}$ can cause an allergic reaction. The wastage rate of $\mathrm{CR}$ is very high during use and the process of manufacturing. Conventional treatment methods cannot remove $\mathrm{CR}$ effectively. Besides, in anaerobic conditions, CR can be metabolized into human carcinogen known as benzidine $[56,57]$.

The reduction of $\mathrm{CR}$ was carried out in the presence of CuNPs and $\mathrm{NaBH}_{4}$. For the reduction, $3 \mathrm{ml}$ of $0.03 \mathrm{~mm}$ CR solution was taken in a quartz cuvette and then $0.5 \mathrm{ml}$ of $\mathrm{NaBH}_{4}$ was added to the solution. The UV-visible 
spectrum of CR gives two strong absorption peaks at 493 and $344 \mathrm{~nm}$. In the absence of a catalyst, the peak intensity remains unchanged. However, with the addition of $5 \mathrm{mg}$ of CuNPs, the decrease in peak intensity at both 493 and $344 \mathrm{~nm}$ started. The reduction of CR was recorded by measuring their UV-visible spectra with a constant time interval of $1 \mathrm{~min}$ between measurements, as shown in Figure 7B. With the addition of CuNPs, the intensity of both peaks decreases. However, a new peak appeared at $252 \mathrm{~nm}$ with increasing intensity, as shown in Figure 7B. Thus, the gradual disappearance of peaks at 493 and $344 \mathrm{~nm}$ was due to the degradation of CR. Thus, the formation of a new peak at $252 \mathrm{~nm}$ was from the generation of free amino group compounds during the CR reduction.

Percent reduction of the CR was calculated from the plot of UV-visible spectra by using equation (2). Here, 90.35\% reduction of CR in the presence of $\mathrm{NaBH}_{4}$ and CuNPs takes place in $5 \mathrm{~min}$, as shown in Figure 7C. It has been reported in the literature that $\mathrm{NaBH}_{4}$ cannot reduce CR alone, even if used in excess; therefore, the reduction of CR follows the pseudo-first order kinetics [58]. The apparent rate constant $\left(k_{\text {app }}\right)$ was calculated from the plot of $\ln \left(A_{t} / A_{0}\right)$ versus time of reduction (as given in Figure 7D) using equation (3). The $k_{\text {app }}$ calculated from the slope for CR was $5.07 \times 10^{-3} \mathrm{~s}^{-1}$.

\subsection{Stability and reusability of CuNPs}

Nowadays, the recyclability and reusability of the catalyst is an important issue in catalysis because a large number of catalysts are deactivated after the first or second cycle and then discarded. Reusability and stability of catalysts are important for determining the performance of catalyst as the active and stable catalyst could considerably decrease the cost of the process. Here, we used MO dye to study the reusability of CuNPs catalyst. The reusability of the CuNPs was checked four times for a 95\% MO reduction. The reusability of the CuNPs was carried out after centrifugation of catalyst from the reaction mixture and then washing with freshly prepared DI water and then reused again following the same experimental procedure of MO reduction. For the first use, CuNPs takes $4 \mathrm{~min}$ for 96\% MO degradation, whereas for the second use, it took 6 min for 95\% MO degradation. Similarly, it took 10 and $15 \mathrm{~min}$ for a 95\% reduction on the third and fourth cycles, respectively, as shown in Figure 8. The reusability study showed that CuNPs possess outstanding stability and recyclability. Thus, it was concluded that CuNPs catalyst could be used several times in various chemical reactions as an active catalyst. The decrease in the

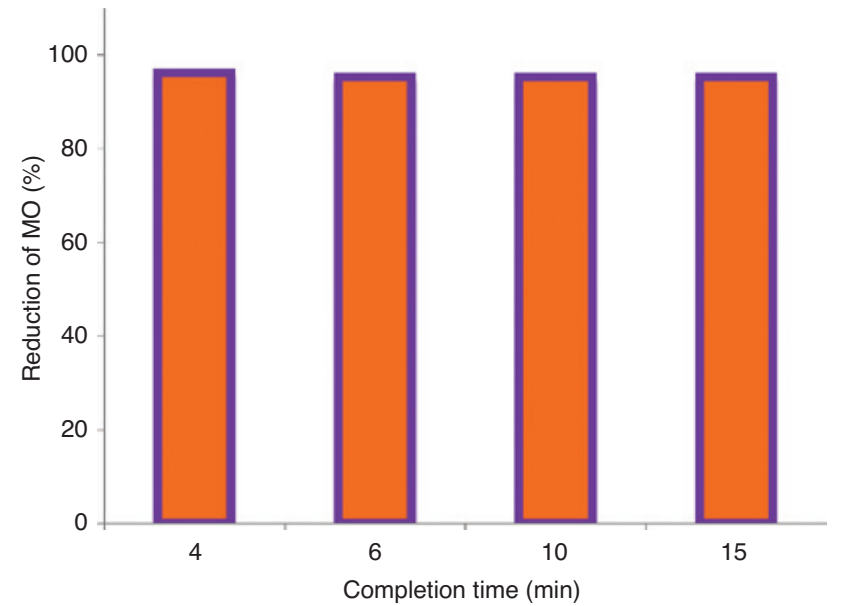

Figure 8: Reusability of CuNPs in the catalytic reduction of MO.

catalytic activity may be due to the oxidation of copper into copper oxide.

\section{Conclusion}

Here, CuNPs were successfully prepared for the first time using $D$. erecta fruit extract, in which the plant extract acts as a capping as well as a reducing agent. Initially, the formation of nanoparticles was confirmed through UV-visible spectrophotometer due their surface plasmon resonance. FT-IR spectra confirmed that biomolecules of $D$. erecta fruit were responsible for the reduction capping of CuNPs. The prepared CuNPs were structurally and morphologically characterized by using FE-SEM, EDX, TGA, and XRD. The CuNPs exhibit outstanding performance in the catalytic reduction of carcinogenic azo dyes MO and CR. Considering the excellent catalytic performance; the prepared CuNPs catalyst can be synthesized in large quantities due to their low cost, high stability and reusability, and environmentally friendly plant support and thus can be used for the purification of natural water from organic effluents.

Acknowledgments: The authors are highly grateful to the Center of Excellence for Advanced Materials Research; Chemistry Department, King Abdulaziz University, Jeddah, Saudi Arabia; and the Department of Chemistry, Kohat University of Science and Technology, Kohat, Pakistan.

Conflict of interest statement: The authors have no conflict of interest regarding this article. 


\section{References}

[1] Keith LH, Gron LU, Young JL. Chem. Rev. 2007, 107, 2695-2708.

[2] Gul S, Rehan ZA, Khan SA, Akhtar K, Khan MA, Khan MI, Rashid MI, Asiri AM, Khan SB. J. Mol. Liq. 2017, 230, 616-624.

[3] Khan SB, Khan SA, Marwani HM, Bakhsh EM, Anwar Y, Kamal T, Asiri AM, Akhtar K. RSC Adv. 2016, 6, 110077-110090.

[4] Khan SB, Akhtar K, Rahman MM, Asiri AM, Seo J, Alamry KA, Han H. New J. Chem. 2012, 36, 2368-2375.

[5] Gopinath V, Priyadarshini S, Priyadharsshini NM, Pandian K, Velusamy P. Mater. Lett. 2013, 91, 224-227.

[6] Gul S, Ismail M, Khan MI, Khan SB, Asiri AM, Rahman IU, Khan MA, Kamboh MA. Asian Pac. J. Trop. Dis. 2016, 6, 311-316.

[7] Haider S, Kamal T, Khan SB, Omer M, Haider A, Khan FU, Asiri AM. Appl. Surf. Sci. 2016, 387, 1154-1161.

[8] Kamal T, Khan SB, Asiri AM. Cellulose 2016, 23, 1911-1923.

[9] Salavati-Niasari M, Davar F, Mir N. Polyhedron 2008, 27, 3514-3518.

[10] Zhao Y, Zhu J-J, Hong J-M, Bian N, Chen H-Y. Eur. J. Inorg. Chem. 2004, 2004, 4072-4080.

[11] Yeh M-S, Yang Y-S, Lee Y-P, Lee H-F, Yeh Y-H, Yeh C-S. J. Phys. Chem. B 1999, 103, 6851-6857.

[12] Kim YH, Kang YS, Lee WJ, Jo BG, Jeong JH. Mol. Cryst. Liq. Cryst. 2006, 445, 231/[521]-238/[528].

[13] Rajesh KM, Ajitha B, Reddy YAK, Suneetha Y, Reddy PS. Optik 2018, 154, 593-600.

[14] Khan SA, Khan SB, Asiri AM. Sci. Rep. 2016, 6, 35107.

[15] Ali F, Khan SB, Kamal T, Alamry KA, Asiri AM, Sobahi TR. Sci. Rep. 2017, 7, 16957.

[16] Pirillo S, Einschlag FSG, Ferreira ML, Rueda EH. J. Mol. Catal. B: Enzym. 2010, 66, 63-71.

[17] Nasrollahzadeh M, Atarod M, Jaleh B, Gandomirouzbahani M. Ceram. Int. 2016, 42, 8587-8596.

[18] Ayed L, Mahdhi A, Cheref A, Bakhrouf A. Desalination 2011, 274, 272-277.

[19] Khazaei M, Khazaei A, Nasrollahzadeh M, Tahsili MR. Tetrahedron 2017, 73, 5613-5623.

[20] Belessi V, Romanos G, Boukos N, Lambropoulou D, Trapalis C. J. Hazard. Mater. 2009, 170, 836-844.

[21] Nasrollahzadeh M, Maham M, Rostami-Vartooni A, Bagherzadeh M, Sajadi SM. RSC Adv. 2015, 5, 64769-64780.

[22] Nasrollahzadeh M, Sajadi SM, Khalaj M. RSC Adv. 2014, 4, 47313-47318.

[23] Nasrollahzadeh M, Sajadi SM, Rostami-Vartooni A, Bagherzadeh M. J. Colloid Interface Sci. 2015, 448, 106-113.

[24] Nasrollahzadeh M, Sajjadi M, Sajadi SM. Chin. J. Catal. 2018, 39, 109-117.

[25] Nasrollahzadeh M, Issaabadi Z, Sajadi SM. RSC Adv. 2018, 8, 3723-3735.

[26] Jain N, Pathak D, Mishra P, Jain S. J. Iran. Chem. Soc. 2009, 6, 77-81.

[27] Dwivedi AD, Gopal K. Colloids Surf. A 2010, 369, 27-33.

[28] Jayaseelan C, Ramkumar R, Rahuman AA, Perumal P. Ind. Crops Prod. 2013, 45, 423-429.

[29] Maham M, Nasrollahzadeh M, Sajadi SM, Nekoei M. J. Colloid Interf. Sci. 2017, 497, 33-42.
[30] Yıldız N, Ateş Ç, Yılmaz M, Demir D, Yıldız A, Çalımlı A. Green Process. Synth. 2014, 3, 259-270.

[31] Maryami M, Nasrollahzadeh M, Mehdipour E, Sajadi SM. Int. J. Hydro. Energy 2016, 41, 21236-21245.

[32] Das S, Das J, Samadder A, Bhattacharyya SS, Das D, KhudaBukhsh AR. Colloids Surf. B 2013, 101, 325-336.

[33] Rahman MM, Khan SB, Gruner G, Al-Ghamdi MS, Daous MA, Asiri AM. Electrochim. Acta. 2013, 103, 143-150.

[34] Sankar R, Karthik A, Prabu A, Karthik S, Shivashangari KS, Ravikumar V. Colloids Surf. B 2013, 108, 80-84.

[35] Cerchier P, Dabalà M, Brunelli K. Green Process. Synth. 2017, 6, 311-316.

[36] Issaabadi Z, Nasrollahzadeh M, Sajadi SM. J. Clean. Prod. 2017, 142, 3584-3591.

[37] Ismail M, Khan MI, Khan SB, Khan MA, Akhtar K, Asiri AM. J. Mol. Liq. 2018, 260, 78-91.

[38] Ahmad T, Wani IA, Manzoor N, Ahmed J, Asiri AM. Colloids Surf. B 2013, 107, 227-234.

[39] Serizawa T, Hirai Y, Aizawa M. Langmuir 2009, 25, 1222912234.

[40] Valodkar M, Rathore PS, Jadeja RN, Thounaojam M, Devkar RV, Thakore S. J. Hazard. Mater. 2012, 201, 244-249.

[41] Nasrollahzadeh M, Sajadi SM, Hatamifard A. Appl. Catal. B Environ. 2016, 191, 209-227.

[42] Nekouei F, Nekouei S, Tyagi I, Gupta VK. J. Mol. Liq. 2015, 201, 124-133.

[43] Agarwal S, Tyagi I, Gupta VK, Ghaedi M, Masoomzade M, Ghaedi AM, Mirtamizdoust B. J. Mol. Liq. 2016, 218, 354-362.

[44] Tajbakhsh M, Alinezhad H, Nasrollahzadeh M, Kamali TA. J. Alloys Compd. 2016, 685, 258-265.

[45] León G, García F, Miguel B, Bayo J. Desalin. Water Treat. 2016, 57, 17104-17117.

[46] Omidvar A, Jaleh B, Nasrollahzadeh M, Dasmeh HR. Chem. Eng. Res. Design 2017, 121, 339-347.

[47] Munagapati VS, Yarramuthi V, Kim D-S. J. Mol. Liq. 2017, 240, 329-339.

[48] Maryami M, Nasrollahzadeh M, Mehdipour E, Sajadi SM. Sep. Purif. Technol. 2017, 184, 298-307.

[49] Nasrollahzadeh M, Issaabadi Z, Sajadi SM. Sep. Purif. Technol. 2018, 197, 253-260.

[50] Bordbar M, Negahdar N, Nasrollahzadeh M. Sep. Purif. Technol. 2018, 191, 295-300.

[51] Rehman Su, Siddiq M, Al-Lohedan H, Sahiner N. Chem. Eng. J. 2015, 265, 201-209.

[52] Khan MM, Lee J, Cho MH. J. Ind. Eng. Chem. 2014, 20, 1584-1590.

[53] Ilayaraja M, Krishnan N, Kannan RS. IOSR J. Environ. Sci. Toxicol. Food Technol. 2013, 5, 79-89.

[54] Dawood S, Sen TK. Water Res. 2012, 46, 1933-1946.

[55] Chatterjee S, Chatterjee S, Chatterjee BP, Guha AK. Colloids Surf. A 2007, 299, 146-152.

[56] Chen H, Zhao J. Adsorption 2009, 15, 381-389.

[57] Chatterjee S, Lee DS, Lee MW, Woo SH. Bioresour. Technol. 2009, 100, 2803-2809.

[58] Tanwar R, Kumar S, Mandal UK. J. Photochem. Photobiol. A 2017, 333, 105-116. 